\title{
Hypothalamic Regulation of Sleep
}

\author{
Rafael Salin-Pascual, M.D., Dmitry Gerashchenko, Ph.D., MaryAnn Greco, Ph.D.,
} Carlos Blanco-Centurion, M.S., and Priyattam J. Shiromani, Ph.D.

The recent discovery linking narcolepsy, a sleep disorder characterized by very short REM sleep latency, with a neuropeptide that regulates feeding and energy metabolism, provides a way to understand how several behaviors may be disrupted as a result of a defect in this peptide. In this chapter we review the evidence linking hypocretin and sleep, including our own studies, and propose that a defect in the lateral hypothalamus that also involves the hypocretin neurons is likely to produce a disturbance in sleep, mood, appetite, and rhythms.

[Neuropsychopharmacology 25:S21-S27, 2001]

(C) 2001 American College of Neuropsychopharmacology.

Published by Elsevier Science Inc.
KEY WORDS: Depression; Narcolepsy; Hypothalamus; Sleep; Appetite; Biological rhythms

It is a privilege to write this chapter honoring Dr. Gillin who was a mentor to two of us (RSP and PJS). Dr. Gillin has been interested in the neurobiology of sleep and has published landmark studies on the relationship between sleep and mood disorders. His lesson to us was a simple one: Whatever you do make sure that it is hypothesis driven and clinically relevant. In his laboratory we examined the role of the cholinergic system in rapid eye movement (REM) sleep generation and how changes in the cholinergic system could influence mood. We focused on the pontine cholinergic REM sleep circuit because of the evidence that sleep-wakefulness and in particular REM sleep were generated from the brainstem, and we wanted to determine how such a circuit might produce the short-REM sleep latency that is evident in depression. However, in drawing up a hypothesisdriven neuronal circuit model we always found it difficult to link the brainstem sleep circuit with hypothalamic mechanisms that control other behaviors, such as, mood,

From the West Roxbury VA Medical Center and Harvard Medical School, 1400 VFW Parkway, West Roxbury, MA 02132

Address correspondence to: Priyattam J. Shiromani, Ph.D West Roxbury VA Medical Center and Harvard Medical School, 1400 VFW Parkway, West Roxbury, MA 02132 E-mail: pshiromani@ hms.harvard.edu appetite, sexual drive, rhythms and endocrine function. We now believe that such a connection between sleep and hypothalamic behaviors can be made as a result of the recent evidence linking the hypothalamic peptide hypocretin with narcolepsy. In this chapter we review the recent evidence identifying hypothalamic sleep and wake neurotransmitter populations and propose that the hypothalamus plays a more important role in regulating states of consciousness then previously believed. By placing sleep regulation in the hypothalamus, it is easier to understand how a defect in this region could also produce a disturbance in other behaviors.

\section{THE PREOPTIC AREA AND SLEEP}

Nauta's experiments led him to conclude that there was a sleep center because discrete lesions of the preoptic area (POA) produced insomnia (Nauta 1946). In the succeeding years, a great body of evidence has accumulated to support Nauta's conclusions (for review see Shiromani 1998; Szymusiak 1995) and also has identified the neurotransmitter of the sleep-active neurons (Sherin et al. 1996).

Sleep active neurons are found in the POA and adjacent basal forebrain (BF) in rats, cats and rabbits (Findlay and Hayward 1969; Kaitin 1984; Szymusiak and 
McGinty 1986a, b; Koyama and Hayaishi 1994). These neurons begin to fire during drowsiness and peak activity is seen during non-REM sleep. The sleep active cells comprise about $25 \%$ of the recorded cells in the BF-POA and are intermixed with wake-active cells which predominate (Koyama and Hayaishi 1994). We have used c-Fos to identify sleep-active neurons located in the ventral lateral preoptic area (VLPO) (Sherin et al. 1996). The VLPO Fos-ir cells project to the histaminergic cells in the tuberomammillary nucleus TMN) and to the brainstem monoaminergic groups (Sherin et al. 1998). The VLPO cells contain GABA and galanin and could inhibit the wake-active cells populations to which they project. Electrophysiology studies have shown that VLPO cells are sleep active (Szymusiak et al. 1998), and in-vitro slice studies have shown that these cells are inhibited by acetylcholine, serotonin and norepinephrine (wake-active neurotransmitters) (Gallopin et al. 2000). Excitotoxic lesions of the VLPO produce insomnia ( $\mathrm{Lu}$ et al. 2000).

Based on this evidence, sleep could occur as a result of increased activity of preoptic area and VLPO GABA neurons which project to and inhibit the wake-active neurons located in the posterior hypothalamus and brainstem.

\section{POSTERIOR HYPOTHALAMUS, HYPOCRETIN AND WAKEFULNESS}

von Economo (1930) believed that the posterior hypothalamus contained a "wake center" because he observed that patients suffering from the viral encephalitic epidemic of 1918 were excessively sleepy and post-mortem analysis revealed damage to the posterior hypothalamus. Since then the role of the posterior hypothalamus in wakefulness has remained largely unexplored except for a few lesion studies which have given inconsistent results. However, in the past year, the identification that narcolepsy is associated with a lesion of hypocretin neurons proves that von Economo was correct in concluding that the posterior hypothalamus contains neurons important for wakefulness.

\section{HYPOCRETIN NEURONS AND RECEPTORS}

The peptide hypocretin, also known as orexin, was discovered by two independent groups using different approaches (De Lecea et al. 1998; Peyron et al. 1998; Sakurai et al. 1998). Pre-prohypocretin is cleaved by proteolytic processing into two smaller peptides, hypocretin-1/orexin A (33 amino acids) and hypocretin-2/orexin B (28 amino acids). The distribution of hypocretin-containing neurons has been made in the mouse (Sakurai et al.
1998; Wagner et al. 2000), rat (De Lecea et al. 1998; Peyron et al. 1998; Nambu et al. 1999), cat (Wagner et al. 2000) and humans (Peyron et al. 2000; Thannickal et al. 2000). Neurons containing hypocretin are found only in the lateral hypothalamus (LH) from where they innervate virtually the entire brain and spinal cord (De Lecea et al. 1998; Peyron et al. 1998; Sakurai et al. 1998; Nambu et al. 1999). Because of the location of the hypocretin neurons in a region that has been implicated in feeding, this neuropeptide was initially thought to regulate appetite and energy metabolism (Sakurai et al. 1998). Application of hypocretin stimulates feeding (Dube et al. 1999; Sweet et al. 1999).

Two orexin receptors have been identified and the distribution of the receptor mRNA levels has been determined (Trivedi et al. 1998). Orexin 1 (hypocretin 1) receptor mRNA is more abundant in ventromedial hypothalamic nucleus, hippocampal formation, DR and LC. In the rat, orexin-2 receptor mRNA is mainly expressed in cerebral cortex, nucleus accumbens, subthalamic and paraventricular thalamic nuclei, and posterior pretectal nuclei (Trivedi et al. 1998; Date et al. 1999). The LC receives the heaviest projection of orexincontaining fibers and intraventricular administration of orexin A or hypocretin-2/orexin B excites LC neurons (Hagan et al. 1999; Horvath et al. 1999b). Orexin-containing terminals are also found in areas implicated in wakefulness such as the LC, TMN, the DR, and the basal forebrain (BF) (Peyron et al. 1998). Because of these projections to neuronal populations implicated in wakefulness, it is believed that orexin promotes wakefulness (Peyron et al. 1998).

Our group recently began to map the distribution of the hypocretin receptor protein in the dorsolateral pons, a site associated with REM sleep generation. Immunohistochemistry indicates that one or both of the receptor subtypes are expressed in the DR, the lateral dorsal tegmental nucleus (LDT), LC, the locus subcoeruleus, pontis oralis, Barrington's nucleus, the trigeminal complex (mesencephalic trigeminal and motor nucleus of the trigeminal nerve), the dorsal tegmental nucleus of Gudden (DTG), the ventral cochlear nucleus, trapezoid nucleus, pontine raphe nucleus and the pontine reticular nucleus. Complementary analysis of hypocretin-R mRNA with a cRNA probe shows that hypocretin receptor mRNA is also detected in areas that show protein immunoreactivity, suggesting the mRNA and protein are co-localized (Greco and Shiromani 2001).

Our results indicate that hypocretin-R1 is the predominant subtype expressed in the LC, DRN and the LDT, brain regions associated with REM sleep generation. On the other hand, the hypocretin-R2 is mutated in canine narcolepsy, which makes it unclear how the hypocretin-1 receptor on pontine neurons might regulate REM sleep. The presence of the receptor on a variety of neuronal phenotypes in the pons indicates that 
the hypocretin system has a multi-functional role. These functions include mastication, bladder control, gastrointestinal function and arousal. Given these projection sites and the functions associated with these sites, we hypothesize that hypocretin acts to keep the animal alert and vigilant while engaged in feeding behavior.

\section{HYPOCRETINS AND NARCOLEPSY}

The hypocretins were linked to narcolepsy as a result of the finding that canines with narcolepsy possess a mutation in the hypocretin-2 receptor (Lin et al. 1999). This was then supported by the finding that mice with deletion of the hypocretin/orexin gene exhibit symptoms of narcolepsy (Chemelli et al. 1999). Recently, it was discovered that narcoleptic patients have a loss of the hypocretin-containing neurons (Peyron et al. 2000; Thannickal et al. 2000) and low CSF concentrations of HCRT-1 (Nishino et al. 2000).

Lesions of the posterior hypothalamus where the hypocretin neurons are located have produced inconsistent effects on sleep. Ranson (1939), Nauta (1946), and Shoham and Teitelbaum (1982) observed behavioral signs of sleepiness following electrolytic lesions of the posterior hypothalamus but these studies did not report the daily amounts of sleep which makes it difficult to conclude whether the behavioral symptoms were isolated or pervasive. Moreover, when Ranson and Nauta did their studies, REM sleep had not yet been discovered. Swett and Hobson (1968) reported finding increased slow wave sleep (SWS) accompanied by behavioral rigidity in some cats, but their electrolytic lesions encompassed the ventral tegmental area. They did not observe narcoleptic-like behavior in the cats. On the other hand, they observed that the cats were cataleptic, not cataplectic. McGinty (1969) recorded sleep EEG from rats with large electrolytic lesions of the posterior hypothalamus that included the lateral hypothalamus and observed hypersomnia in two of seven lesioned rats for 5-8 days after the lesion followed by hyposomnia in all rats; REM sleep was suppressed or decreased. Jurkowlaniec et al. (1994) found that electrolytic lesion of the LH resulted in a decrease in SWS and REM sleep during the day cycle but the night cycle sleep was unchanged. They concluded that LH lesions produced hyposomnia. Ibotenic acid lesion, which would spare fibers of passage has also not produced consistent effects. In two studies from the same laboratory (Denoyer et al. 1991; Sallanon et al. 1988), ibotenic acid applied to the posterior hypothalamus produced a hypersomnia for 1-4 days followed by hyposomnia; REM sleep was increased only during the first 3-21 hours. In these lesion studies, no attempts were made to specifically identify the phenotype of the neurons that were lesioned, and the inconsistent effects on sleep might have occurred because the lesion methods did not destroy the appropriate neurons.

To specifically test the hypothesis that lesions of the LH which result in loss of hypocretin-containing neurons produce symptoms of narcolepsy, we have created a neurotoxin by conjugating the ribosomal inactivating protein, saporin (Stirpe et al. 1992), to the hypocretin/ orexin receptor binding ligand, hypocretin-2/orexin-B. The hypocretin-containing neurons have been shown to have an autoreceptor (Horvath et al. 1999a), and we reasoned that the neurotoxin would lesion these neurons. We found that when the neurotoxin was administered to the $\mathrm{LH}$, the hypocretin-immunoreactive neurons were lesioned and the rats had sleep fragmentation, excessive sleepiness, increase in REM sleep, and sleep onset REM sleep periods (SOREMPs), symptoms which are characteristic of narcolepsy in humans, dogs and hypocretin null mice. The hypersomnia and SOREMPs were negatively correlated with the loss of hypocretin neurons. This finding demonstrates that a defect in the $\mathrm{LH}$ that also involves the hypocretin neurons produces narcoleptic-like sleep behavior in rats.

Is it the loss of the hypocretin neurons or the loss of the hypocretin innervation at target sites that causes the sleep disturbance in narcolepsy? The hypocretin neurons project to sites involved in wakefulness and REM sleep. The heaviest projections are to the LC (Figure 1) and the TMN. Hypocretin fibers also innervate the DR and BF. The BF, TMN, DR and LC have been implicated in wakefulness based on electrophysiological studies which have found that neurons in these regions are preferentially wake-active and quiescent during non-REM sleep. DR and LC neurons are silent during REM sleep (for review see Shiromani et al. 1987). Single-cell recording studies of the type conducted by sleep researchers are by definition correlational, yet investigators have been quick to infer a cause-and-effect. Moreover, historically, lesions of the DRN, LC or the BF have never been shown to produce hypersomnia, increased REM sleep, SOREMPs or other narcoleptic-like behaviors. Thus, it is not clear how activity of the LC, DRN, BF or the TMN produces wakefulness and inhibits REM sleep.

Alternatively, we suggest that the change in firing of the brainstem cholinergic and aminergic neurons including any imbalance in the aminergic versus cholinergic tone may actually result from a reduction in function of LH neurons, in particular neurons that contain hypocretin. If one supposes that the brainstem cholinergic and aminergic neurons are controlled by hypothalamic hypocretin neurons, then the emphasis shifts to the hypothalamus. This also enables a way to understand how an abnormality in neurons in the same brain region, i.e, hypothalamus, might produce disturbance in sleep, mood, feeding, sexual drive, and biological rhythms. 

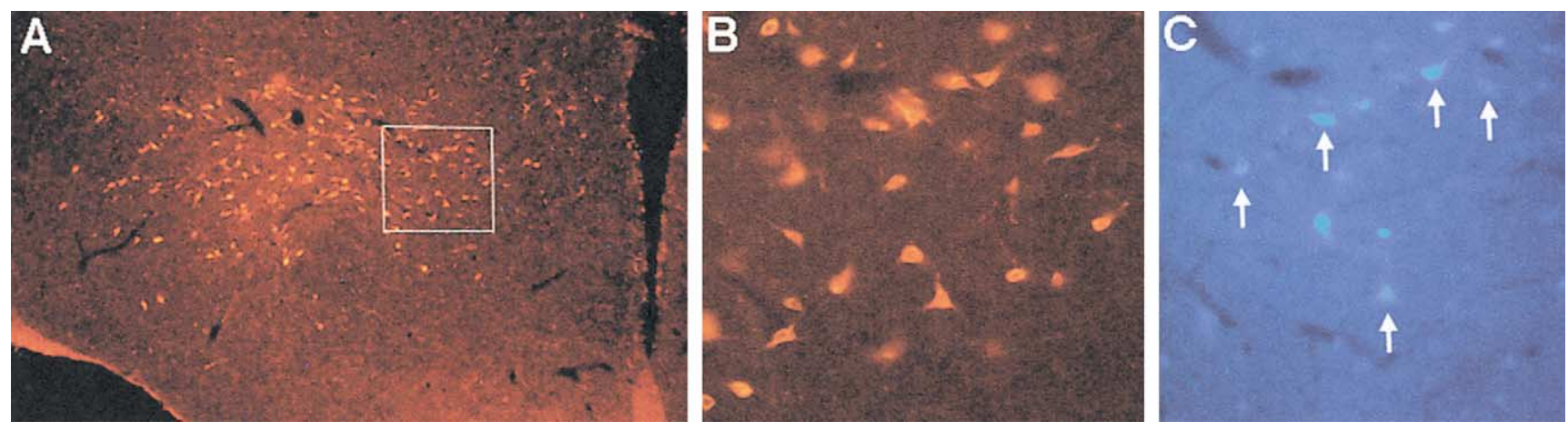

Figure 1. Hypocretin-containing neurons in the lateral hypothalamus project monosynaptically to the locus coeruleus. The retrograde tracer Fast Blue was injected using a glass micropipette into the LC (unilateral injection; $500 \mathrm{nl}$ ) and the lateral hypothalamus was examined for somata containing the tracer. Panel A depicts a coronal section (30 um thick) of the hypocretin-containing neurons in the lateral hypothalamus. The neurons in the region represented by the square are shown in Panel B and many of these neurons were found to contain the retrograde tracer Fast Blue (Panel C). White arrows in Panel C identify Fast Blue-containing cells that are also hypocretin-positive (Panel B).

\section{HYPOCRETIN AND DEPRESSION}

Patients with major depression have short REM sleep latency, increase in the length of the first REM sleep period, increased REM density, and a decrease in delta sleep (summarized in Shiromani et al. 1987). A disturbance in biological rhythms has been implicated in this disorder (Shiromani et al. 1987). Seasonal affective disorder, or "winter depression" is one example of how changes in external light cues affects mood. Light therapy has proven to be effective in treating this type of depression. REM sleep deprivation, as well as total sleep deprivation, also has an antidepressant effect, although the underlying mechanism is not known. As part of the clinical symptoms, a change in appetite and weight are reported in depressed patients. In winter depression, patients report a craving for carbohydrates and patients gain weight.

Because of the short REM sleep latency and the appetite disturbance we suggest that in depression, including winter depression, there might be a reduction in hypocretin secretion. Examining the levels of hypocretin across the $24 \mathrm{~h}$ in patients with depression, including winter depression, could test this. The suprachiasmatic nucleus projects to the posterior hypothalamus, including the LH (Watts et al. 1987; Watts and Swanson 1987). A defect in the lateral hypothalamus, including the hypocretin neurons, could result in an attenuated signal being received from the SCN, and this could produce abnormal rhythms.

Animal models of depression could be used to test the link between the LH, hypocretin and depression. For example, the Wistar-Kyoto (WKY) rats are hypoactive, have reduced exploratory behavior, and increased immobility in the Porsolt swim test (Pare 1994). WKY rats also have increased REM sleep (Dugovic et al.
2000). WKY rats have decreased hypocretin immunoreactivity (measured using RIA) and reduced levels of hypocretin $\mathrm{mRNA}$, indicating a reduction in hypocretin (Taheri et al. 2001). It will be important to determine whether there is a phase-advance in circadian rhythms in these rats. Another model is the Flinders Sensitive Line (FSL) (for review see Overstreet 1986). The FSL rats have increased REM sleep and short REM sleep latency (Shiromani et al. 1988). The FSL rats also have phase-advance and shorter period of the temperature rhythm (Shiromani et al. 1991; Shiromani and Overstreet 1994). The hypocretin system has not been explored in these rats. Another rodent model of depression is the one developed by Vogel (Vogel et al. 1990) where administration of clomipramine in neonatal rats produces depressive-like symptoms in adulthood. In this model also, it will be important to determine whether there is a reduction in hypocretin function. Prenatal stress has been shown to produce symptoms of depression such as reduced latency to the onset of REM sleep, prolongation of the first REM episode, and diminished SWS (Rao et al. 1999). Because of the link between stress and depression, it will be useful to investigate whether there is a reduction in hypocretin levels during stress.

\section{HYPOCRETIN AND NIGHT-EATING SYNDROME}

Patients with night-eating syndrome display morning anorexia, evening hyperphagia, and insomnia (Schenck and Mahowald 1994). In a recent study, Birketvedt et al. (1999) surveyed 10 obese subjects with night-eating syndrome and 10 control subjects without NES, matched for age, sex and weight. The number of calories consumed by the two groups per 24-h interval was similar. 
However, subjects with night-eating syndrome recorded an average of 9.3 eating episodes per 24-h interval, and this was significantly more than the average 4.2 episodes recorded by controls. Between 8 P.M. and 6 A.M. night-eating syndrome patients consumed $56 \%$ of their daily energy intake compared with $15 \%$ consumed by control subjects. Given the recent discovery of hypocretin and its relation to appetite and sleep, it will be very important to determine whether night-eating syndrome patients demonstrate a disturbance in leptin or orexin/ hypocretin levels.

\section{HYPOCRETIN AND OBSTRUCTIVE SLEEP APNEA (OSA)}

Obstructive sleep apnea is a disorder in which, during sleep, the upper airway collapses and airflow is interrupted, which then forces the individual to awaken and resume breathing. As a result of the cessation of breathing during sleep, the individual is not able to maintain long bouts of sleep and fails to enter into the deeper stages of sleep, ie., stages 3 and 4 . Obesity is a risk factor in that fatty deposits in the upper airway produce a narrowing of the upper airway, which then leads to cessation of airflow during sleep. The levels of orexin/ hypocretin have not been measured in obese individuals. Obese patients have an increase in leptin levels (Halle et al. 1999; Scheen and Luyckx 1999). Although leptin is considered to be a satiety signal to stop eating, it is not clear why the increased leptin levels in obese individuals does not stop food intake. Hypocretin neurons posses leptin receptors (Hakansson et al. 1999; Horvath et al. 1999a), and this might be part of the feedback regulatory process that controls of food intake. One possibility is that the increased sleep fragmentation in these patients produces a sleep loss which increases energy metabolism. As a consequence the individual eats more, but this may only serve to occlude the upper-airway further, leading to more sleep loss. As such a vicious cycle of sleep loss and increased food intake may be occurring in these patients. In rats, sleep deprivation has been shown to increase energy expenditure and increased food intake (Rechtschaffen et al. 1989; Balzano et al. 1990). Measurement of orexin/ hypocretin levels before and during CPAP treatment in these patients could provide clues about regulatory role of this neuropeptide in OSA.

\section{CONCLUSION}

The discovery of hypocretin, its link with sleep, and the fact that these neurons are located in the part of the brain that also regulates other behaviors, provides a way to understand psychiatric disorders where the ma- jor symptoms are feeding disturbance, loss of sexual drive, abnormality in endocrine rhythms, hypersomnia and short REM sleep latency.

\section{REFERENCES}

Balzano S, Bergmann BM, Gilliland MA, Silva JE, Rechtschaffen A, Refetoff S (1990): Effect of total sleep deprivation on 5'-deiodinase activity of rat brown adipose tissue. Endocrinology 127:882-890

Birketvedt GS, Florholmen J, Sundsfjord J, Osterud B, Dinges D, Bilker W, Stunkard A (1999): Behavioral and neuroendocrine characteristics of the night-eating syndrome. JAMA 282:657-663

Chemelli RM, Willie JT, Sinton CM, Elmquist JK, Scammell T, Lee C, Richardson JA, Williams SC, Xiong $Y$, Kisanuki Y, Fitch TE, Nakazato M, Hammer RE, Saper CB, Yanagisawa M (1999): Narcolepsy in orexin knockout mice: molecular genetics of sleep regulation. Cell 98:437-451

Date Y, Ueta Y, Yamashita H, Yamaguchi H, Matsukura S, Kangawa K, Sakurai T, Yanagisawa M, Nakazato M (1999): Orexins, orexigenic hypothalamic peptides, interact with autonomic, neuroendocrine and neuroregulatory systems. Proc Natl Acad Sci USA 96:748-753

De Lecea L, Kilduff TS, Peyron C, Gao X, Foye PE, Danielson PE, Fukuhara C, Battenberg EL, Gautvik VT, Bartlett FS, Frankel WN, Van den Pol AN, Bloom FE, Gautvik KM, Sutcliffe JG (1998): The hypocretins: hypothalamus-specific peptides with neuroexcitatory activity. Proc Natl Acad Sci USA 95:322-327

Denoyer M, Sallanon M, Buda C, Kitahama K, Jouvet M (1991): Neurotoxic lesion of the mesencephalic reticular formation and/or the posterior hypothalamus does not alter waking in the cat. Brain Res 539:287-303

Dube MG, Kalra SP, Kalra PS (1999): Food intake elicited by central administration of orexins/hypocretins: identification of hypothalamic sites of action. Brain Res 842:473-477

Dugovic C, Solberg LC, Redei E, Van Reeth O, Turek FW (2000): Sleep in the Wistar-Kyoto rat, a putative genetic animal model for depression. NeuroReport 11:627-631

von Economo C (1930): Sleep as a problem of localization. J Nervous and Mental Disease 71:249-259

Findlay ALR, Hayward JN (1969): Spontaneous activity of single neurones in the hypothalamus of rabbits during sleep and waking. J Physiol. 201:237-258

Gallopin T, Fort P, Eggermann E, Cauli B, Luppi P-H, Rossier J, Audino MG, Muhlethaler M, Serafin M (2000): Identification of sleep-promoting neurons in vitro. Nature 404:992-995

Greco MA, Shiromani PJ (2001): Hypocretin receptor protein and mRNA expression in the dorsolateral pons of rats. Molec Brain Res 88:176-182

Hagan JJ, Leslie RA, Patel S, Evans ML, Wattam TA, Holmes S, Benham CD, Taylor SG, Routledge C, Hemmati P, Munton RP, Ashmeade TE, Shah AS, Hatcher JP, Hatcher PD, Jones DN, Smith MI, Piper DC, Hunter AJ, Porter RA, Upton N (1999): Orexin A activates locus 
coeruleus cell firing and increases arousal in the rat. Proc Natl Acad Sci USA 96:10911-10916

Hakansson M, De Lecea L, Sutcliffe JG, Yanagisawa M, Meister B (1999): Leptin receptor- and STAT3- immunoreactivities in hypocretin/orexin neurons of the lateral hypothalamus. J Neuroendocrinol 11:653-663

Halle M, Berg A, Garwers U, Grathwohl D, Knisel W, Keul J (1999): Concurrent reductions of serum leptin and lipids during weight loss on obese men with type II diabetes. Amer J Physiol 277:E277-E282

Horvath TL, Diano S, van den Pol A (1999a): Synaptic interaction between hypocretin (orexin) and neuropeptide $Y$ cells in the rodent and primate hypothalamus: A novel circuit implicated in metabolic and endocrine regulations. J Neurosci 19:1072-1087

Horvath TL, Peyron C, Diano S, Ivanov A, Aston-Jones G, Kilduff TS, Van den Pol AN (1999b): Hypocretin (orexin) activation and synaptic innervation of the locus coeruleus noradrenergic system. J Comp Neurol. 415: 145-159

Jurkowlaniec E, Trojniar W, Tokarski J (1994): Daily pattern of EEG activity in rats with lateral hypothalamic lesions. J Physiol Pharmacol 45:399-411

Kaitin K (1984): Preoptic area unit activity during sleep and wakefulness in the cat. Exp Neurol. 83:347-351

Koyama Y, Hayaishi O (1994): Modulation by prostaglandins of activity of sleep-related neurons in the preoptic/ anterior hypothalamic areas in rats. Brain Res Bull 33:367-372

Lin L, Faraco J, Li R, Kadotani H, Rogers W, Lin X, Qiu X, deJong PJ, Nishini S, Mignot E (1999): The sleep disorder canine narcolepsy is caused by a mutation in the hypocretin (orexin) receptor 2 gene. Cell 98:365-376

Lu J, Shiromani PJ, Saper CB (2000): Effects of lesions of the ventral lateral preoptic nucleus on NREM and REM sleep. J Neuroscience 20:3830-3840

McGinty DJ (1969): Somnolence, recovery and hyposomnia following ventromedial diencephalic lesions in the rat. Electroencephalog Clin Neurophysiol. 26:70-79

Nambu T, Sakurai T, Mizukami K, Hosoya Y, Yanagisawa M, Goto K (1999): Distribution of orexin neurons in the adult rat brain. Brain Res 827:243-260

Nauta JH (1946): Hypothalamic regulation of sleep in rats. An experimental study. J Neurophysiol 9:285-316

Nishino S, Ripley B, Overeem S, Lammers GJ, Mignot E (2000): Hypocretin (orexin) deficiency in human narcolepsy. Lancet 355:39-40

Overstreet DH (1986): Selective breeding for increased cholinergic function: development of a new animal model of depression. Biol Psychiatry 21:49-58

Pare WP (1994): Open field, learned helplessness, conditioned defensive burying, and forced-swim tests in WKY rats. Physiol Behav 55:433-439

Peyron C, Faraco J, Rogers W, Ripley B, Overeem S, Charnay Y, Nevsimalova S, Aldrich M, Reynolds D, Albin R, Li R, Hungs M, Pedrazzoli M, Padigaru M, Kucherlapati M, Fan J, Maki R, Lammers GJ, Bouras C, Kucherlapati R, Nishino S, Mignot E (2000): A mutation in a case of early onset narcolepsy and a generalized absence of hypocretin peptides in human narcoleptic brains. Nat Med 6: 991-997.
Peyron C, Tighe DK, Van den Pol AN, De Lecea L, Heller HC, Sutcliffe JG, Kilduff TS (1998): Neurons containing hypocretin (orexin) project to multiple neuronal systems. J Neurosci 18:9996-10015

Ranson SW (1939): Somnolence caused by hypothalamic lesions in the monkey. Arch Neurol Psychiat. 41:1-23

Rao U, McGinty DJ, Shinde A, McCracken JT, Poland RE (1999): Prenatal stress is associated with depressionrelated electroencephalographic sleep changes in adult male rats: A preliminary report. Prog Neuropsychopharmacol Biol Psychiatry 23:929-939

Rechtschaffen A, Bergmann BM, Everson CA, Kushida CA, Gilliland MA (1989): Sleep deprivation in the rat: X. Integration and discussion of the findings. Sleep 12:68-87

Sakurai T, Amemiya A, Ishii M, Matsuzaki I, Chemelli RM, Tanaka H, Williams SC, Richarson JA, Kozlowski GP, Wilson S, Arch JR, Buckingham RE, Haynes AC, Carr SA, Annan RS, McNulty DE, Liu WS, Terrett JA, Elshourbagy NA, Bergsma DJ, Yanagisawa M (1998): Orexins and orexin receptors: a family of hypothalamic neuropeptides and $\mathrm{G}$ protein-coupled receptors that regulate feeding behavior. Cell 92:573-585

Sallanon M, Sakai K, Buda C, Puymartin M, Jouvet M (1988): Increase of paradoxical sleep induced by microinjections of ibotenic acid into the ventrolateral part of the posterior hypothalamus in the cat. Archives Ital Biology 126:87-97

Scheen A, Luyckx FH (1999): Medical aspects of obesity. Acta Chir Belg 99:135-139

Schenck CH, Mahowald MW (1994): Review of nocturnal sleep-related eating disorders. Int J Eating Disorders 15:343-356

Sherin J E, Elmquist JK, Torrealba F, Saper CB (1998): Innervation of histaminergic tuberomammillary neurons by GABAergic and galaninergic neurons in the ventrolateral preoptic neurons of the rats. J Neurosci 18:47054721.

Sherin JE, Shiromani PJ, McCarley RW, Saper CB (1996): Activation of ventrolateral preoptic neurons during sleep. Science 271:216-219

Shiromani P, Rapaport MH, Gillin JC (1987): The neurobiology of sleep: Basic concepts and clinical implications. In Hales RE, Frances AJ (eds), Psychiatry Update: The American Psychiatric Association Annual Review, Volume 6 . Washington, DC, American Psychiatric Press pp 235-259

Shiromani PJ (1998): Sleep Circuitry, Regulation and Function: Lesson from c-Fos, Leptin and Timeless. In Morrison A, Fluharty C (eds), Progress in Psychobiology and Physiological Psychology. San Diego, CA, Academic Press, pp 67-90

Shiromani PJ, Klemfuss H, Lucero S, Overstreet DH (1991): Diurnal rhythm of core body temperature is phase advanced in a rodent model of depression. Biol Psychiat 29:923-930

Shiromani PJ, Overstreet D (1994): Free-running period of circadian rhythms is shorter in rats with a genetically upregulated central cholinergic system. Biol Psychiat 36:622-626

Shiromani P, Overstreet DH, Levy D, Goodrich CA, Campbell SS, Gillin JC (1988): Increased REM sleep in rats 
selectively bred for cholinergic hyperactivity. Neuropsychopharmacol 1:127-133

Shoham S, Teitelbaum P (1982): Subcortical waking and sleep during lateral hypothalamic 'somnolence' in rats. Physiol Behav. 28:323-333

Stirpe F, Barbieri L, Battelli MG, Soria M, Lappi DA (1992): Ribosome-inactivating proteins from plants: present status and future prospects. Biotechnology (NY) 10:405412

Sweet DC, Levine AS, Billington CJ, Katz CM (1999): Feeding response to central orexins Brain Res 821:535-538

Swett CP, Hobson A (1968): The effects of posterior hypothalamic lesions on behavioral and electrographic manifestations of sleep and waking in cats. Arch Ital Biol 106:283-293.

Szymusiak R (1995): Magnocellular nuclei of the basal forebrain: Substrates of sleep and arousal regulation. Sleep 18:478-500

Szymusiak R, Alam MN, Steininger TL, McGinty D (1998): Sleep-waking discharge patterns of ventrolateral preoptic/anterior hypothalamic neurons in rats. Brain Res 803:178-188

Szymusiak R, McGinty D (1986a): Sleep-related neuronal discharge in the basal forebrain of cats. Brain Res 370:82-92

Szymusiak R, McGinty D (1986b): Sleep suppression following kainic acid-induced lesions of the basal forebrain. Exp Neurol 94:598-614
Taheri S, Gardiner J, Hafizi S, Murphy K, Dakin C, Seal L, Small C, Ghatei M, Bloom S (2001): Orexin A immunoreactivity and prepro-orexin mRNA in the brain of Zucker and WKY rats. NeuroReport 12:459-464

Thannickal T, Moore RY, Nienhuis R, Ramanathan L, Gulyani S, Aldrich M, Cornford M, Siegel JM (2000): Reduced number of hypocretin neurons in human narcolepsy. Neuron 27:460-474

Trivedi P, Yu H, MacNeil DJ, Van der Ploeg LH, Guan XM (1998): Distribution of orexin receptor mRNA in the rat brain. FEBS Lett 438:71-75

Vogel G, Neill D, Hagler M, Kors D (1990): A new animal model of endogenous depression: a summary of present findings. Neurosci Biobehav Rev 14:85-91

Wagner D, Salin-Pascual R, Greco MA, Shiromani PJ (2000): Distribution of hypocretin-containing neurons in the lateral hypothalamus and c-Fos immunoreactive neurons in the VLPO. Sleep Research Online 3:35-42

Watts AG, Swanson LW (1987): Efferent projections of the suprachiasmatic nucleus: II. Studies using retrograde transport of fluorescent dyes and simultaneous peptide immunohistochemistry in the rat. J Comp Neurol 258:230-252

Watts AG, Swanson LW, Sanchez-Watts G (1987): Efferent projections of the suprachiasmatic nucleus: I. Studies using anterograde transport of phaseolus vulgaris leucoagglutinin in the rat. J Comp Neurol 258:204-229 